\section{Effect of anesthetic drugs on time production and alpha rhythm*}

\author{
NILLY ADAM and BURTON S. ROSNER \\ University of Pennsylvania, Philadelphia, Pennsylvania 19104 \\ and \\ ELIZABETH C. HOSICK and DONALD L. CLARK
}

Hospital of the University of Pennsylvania, Philadelphia, Pennsylvania 19104

Ss produced time intervals before and during inhalation of low concentrations of anesthetic gases. The drugs increased time productions by raising the slope of the line representing produced against objective time. Alterations in time production were not accompanied by consistent changes in alpha rhythm, respiratory rate, heart rate, or body temperature. The findings argue against the alpha rhythm's acting as the biological pendulum for the internal clock.

A popular theory of time perception supposes that some repetitive bodily process serves as a biological pendulum which drives an internal clock. The $\mathrm{S}$ measures the passage of time with this clock. Several physiological events have been nominated for the role of the pendulum. Among them, the alpha rhythm of the electroencephalogram (EEG) seems an especially attractive candidate. Cardiac or respiratory rhythms can vary suddenly over wide ranges and would make an internal clock quite erratic. In fact, only Hawkes et al (1962) have ever reported a positive correlation between respiratory rate and time perception. The alpha rhythm, however, maintains a reasonably constant frequency which is consistent over days within a given person. Furthermore, alpha frequency increases as body temperature rises (Hoagland, 1936). This effect would explain the frequently observed correlation between body temperature and judgment of time (Francois, 1927; Hoagland, 1933; Kleber et al, 1963; Pfaff, 1968).

Anliker (1963) and Holubar (1969) have investigated the relationship between alpha activity and the sense of time. Anliker examined the correlation between steady self-determined rate of tapping and the integrated voltage of the EEG filtered at the modal frequency of the alpha rhythm. He did not find the correlation which he sought, although a decreased alpha frequency accompanied a slower rate of tapping over a limited range. Holubar worked directly with alpha frequency. He first

\footnotetext{
* Supported in part by Grants 5-P01-GM-09070 and 1-P01-GM-15430 from the National Institutes of Health. National Institute of General Medical Sciences, by Research Training Grant 5-T01-GM-215, and by Grant MH-10848 from the National Institute of Mental Health. We gratefully acknowledge the aid of Dr. Rodney Teichner in conducting the experiments reported here.
}

established a 30-sec, temporally conditioned GSR in human Ss. Then he photically drove the alpha rhythm at different frequencies and observed the interval between conditioned responses. Four of his 15 Ss gave consistent, surprising, and still unexplained results. At driving frequencies of 7 or $14 \mathrm{~Hz}$, the interval between conditioned GSRs decreased to half its usual value of almost $30 \mathrm{sec}$.

Recent incidental observations by Clark et al (1969) suggested a new way of testing the relationship between alpha frequency and perception of time. These investigators noticed that low concentrations of cyclopropane, a general anesthetic, made Ss less aware of the passage of time. Frankenhaeuser (1959) and Robson et al (1960) had reported similar effects in Ss exposed to low concentrations of nitrous oxide. In addition, however, Clark et al saw that their Ss' EEGs contained considerable alpha activity during administration of the drug. These findings led us to study the effects of low concentrations of several different anesthetic gases on the relationship between alpha frequency and judgment of time. We anticipated that low concentrations of anesthetics would make Ss increase their productions of standard time intervals. If so, we could then ascertain if alpha frequency decreased appropriately.

\section{METHOD}

Eight young paid male volunteers were Ss. In a preliminary visit to the hospital, each $S$ heard a full explanation of the aims, procedures, and potential hazards of the project. Only after several days away from the hospital could a $\mathrm{S}$ return to give informed consent. He then provided his medical history and underwent a complete physical examination. He next had a complete blood count, urine analysis, chest X-ray, electrocardiogram, and determinations of blood urea nitrogen and serum glutamic-oxaloaetic transaminase. Ss finally accepted for study had to be within normal limits on each test. Of the eight Ss, J.D. and S.W. each served in two studies involving different anesthetics. Thus, 10 individual studies were done with the eight Ss. Cyclopropane was used in five studied, diethyl ether in one. Penthrane (methoxyflurane) in two, and Ethrane $(1,1,2-t$ riflu or o- 2 -ch loreth yl difluoromethyl ether) in one. The latter two drugs are halogenated ethers.

Ss abstained from all solids, liquids, and drugs for $12 \mathrm{~h}$ prior to the study. During a study, the $\mathbf{S}$ lay supine on an operating table. The EEG was recorded through needle electrodes placed in left frontal $\left(F_{3}\right)$, central $\left(C_{3}\right)$, and parietal $\left(P_{3}\right)$ scalp and at the vertex $\left(\mathrm{C}_{\mathrm{z}}\right)$. Bipolar records were taken on a Grass Model 6 EEG machine between $F_{3}-C_{3}, C_{3}-P_{3}$, $\mathrm{F}_{3}-\mathrm{C}_{2}, \mathrm{C}_{3}-\mathrm{C}_{\mathrm{z}}$, and $\mathrm{P}_{3}-\mathrm{C}_{2}$. Respiratory rate was recorded continuously on a Gilson polygraph. Heart rate and blood pressure were obtained with a clinical sphygmomanometerstethoscope set. A thermistor probe feeding into a Yellow Springs Instrument Co. electronic thermometer provided measurements of rectal temperature. Rectal temperature, heart rate, and blood pressure were recorded every $10 \mathrm{~min}$. Ss produced apparent time intervals by pressing and holding closed a microswitch for various durations requested by the $E$. Responses were recorded on a separate channel of the EEG machine, which was operated at a paper speed of $15 \mathrm{~mm} / \mathrm{sec}$. We selected the method of production because Hawkes et al had shown that experimental variations affect its results the least. It also is the only method which has yielded consistent correlations across $\mathrm{Ss}$ between time judgments and physiological indices. During time productions, the S's eyes were covered, and he was instructed not to count or use any other explicit cues.

After the $\mathrm{S}$ had been prepared for recording, he began breathing room air through a mouthpiece. We then obtained control data. Next, a nonrebreathing anesthesia circuit was connected to the mouthpiece and the anesthetic was administered. The system was vented to the out-of-doors. Concentration was varied individually so that the $S$ could still respond to verbal commands. Inspired and end-tidal concentrations of anesthetic were measured to the nearest $0.05 \%$ by gas chromatography (Hill, 1960). Samples were taken every $10 \mathrm{~min}$ from appropriate points in the anesthesic circuit. Cyclopropane has a low blood/gas solubility coefficient and was administered until the end-tidal 
Table 1

Time Productions and Physiological Indices Before and During Inhalation of Anesthetics

\begin{tabular}{|c|c|c|c|c|c|c|c|c|c|c|}
\hline \multirow[b]{2}{*}{ Study } & \multirow{2}{*}{$\begin{array}{c}\text { Condi- } \\
\text { tiona }^{\mathrm{a}}\end{array}$} & \multicolumn{2}{|c|}{ 20-Sec Production } & \multicolumn{2}{|c|}{ Alpha Frequency } & \multirow[b]{2}{*}{$\mathbf{f}^{\mathbf{b}}$} & \multirow{2}{*}{$\begin{array}{c}T_{R} \\
\left(\mathbf{C}^{\mathbf{0}}\right)^{\mathbf{c}} \\
\end{array}$} & \multirow[b]{2}{*}{ Drugd } & \multicolumn{2}{|c|}{ Concentration $^{e}$} \\
\hline & & Median & Range (Sec) & Median & Range (cps) & & & & 1 & $\mathbf{E}_{\mathbf{T}}$ \\
\hline S. W.1 & $\begin{array}{l}\mathbf{C} \\
\mathbf{A}\end{array}$ & $\begin{array}{l}5.2 \\
9.4\end{array}$ & $\begin{array}{l}\text { 4.9- } 6.8 \\
8.3-11.0\end{array}$ & $\begin{array}{l}9.5 \\
9.5\end{array}$ & $\begin{array}{l}8.5-10.5 \\
9.5-9.5\end{array}$ & $\begin{array}{l}16 \\
15\end{array}$ & $\begin{array}{l}36.6 \\
36.9\end{array}$ & Cyclo & 3.44 & 3.15 \\
\hline R. E. & $\begin{array}{l}\text { C } \\
\text { A }\end{array}$ & $\begin{array}{l}20.5 \\
26.8\end{array}$ & $\begin{array}{l}19.4-21.2 \\
24.0-27.7\end{array}$ & $\begin{array}{l}9.5 \\
9.0\end{array}$ & $\begin{array}{l}8.5-10.5 \\
8.5-10.0\end{array}$ & $\begin{array}{l}14 \\
17\end{array}$ & $\begin{array}{l}37.3 \\
37.3\end{array}$ & Cyclo & 3.19 & 3.13 \\
\hline M. 0 . & $\begin{array}{l}\text { C } \\
\text { A }\end{array}$ & $\begin{array}{l}11.5 \\
20.3\end{array}$ & $\begin{array}{l}10.1-13.5 \\
17.2-24.1\end{array}$ & $\begin{array}{r}10.5 \\
9.2\end{array}$ & $\begin{array}{l}8.5-10.5 \\
8.5-10.5\end{array}$ & $\begin{array}{l}18 \\
16\end{array}$ & $\begin{array}{l}37.1 \\
36.9\end{array}$ & Cyclo & 2.29 & 2.18 \\
\hline B. $\mathbf{M}$. & $\begin{array}{l}\text { C } \\
\text { A }\end{array}$ & $\begin{array}{l}24.3 \\
40.0\end{array}$ & $\begin{array}{l}18.6-27.8 \\
29.6-58.6\end{array}$ & $\begin{array}{l}9.0 \\
8.1\end{array}$ & $\begin{array}{l}8.2-9.5 \\
8.0-9.0\end{array}$ & $\begin{array}{r}6-9 \\
14-15\end{array}$ & $\begin{array}{l}36.5 \\
36.4\end{array}$ & Cyclo & 1.91 & 1.86 \\
\hline B. C. & $\begin{array}{l}\mathbf{C} \\
\mathbf{A}\end{array}$ & $\begin{array}{l}19.9 \\
22.6\end{array}$ & $\begin{array}{l}16.3-26.7 \\
18.9-37.3\end{array}$ & $\begin{array}{l}9.5 \\
9.5\end{array}$ & $\begin{array}{l}8.5-10.0 \\
8.5-10.2\end{array}$ & $\begin{array}{l}10-12 \\
12-14\end{array}$ & $\begin{array}{l}36.5 \\
36.5\end{array}$ & Cyclo & 1.14 & 1.06 \\
\hline J. C.1 & $\begin{array}{l}\text { C } \\
\text { A }\end{array}$ & $\begin{array}{l}26.9 \\
34.8\end{array}$ & $\begin{array}{l}19.0-30.8 \\
31.1-53.4\end{array}$ & $\begin{array}{l}9.0 \\
9.5\end{array}$ & $\begin{array}{l}8.5-10.0 \\
8.5-10.0\end{array}$ & $\begin{array}{l}17-19 \\
12-14\end{array}$ & $\begin{array}{l}36.9 \\
36.9\end{array}$ & Ethr & 0.47 & 0.32 \\
\hline R. H. & $\begin{array}{l}\text { C } \\
\text { A }\end{array}$ & $\begin{array}{l}18.2 \\
27.5\end{array}$ & $\begin{array}{l}18.0-21.3 \\
24.6-30.7\end{array}$ & $\begin{array}{l}9.1 \\
8.5\end{array}$ & $\begin{array}{l}8.2-9.5 \\
8.2-8.8\end{array}$ & $\begin{array}{l}12-13 \\
12-14\end{array}$ & $\begin{array}{l}36.8 \\
37.0\end{array}$ & Ethr & 0.35 & 0.35 \\
\hline J. C.2 & $\begin{array}{l}\text { C } \\
\text { A }\end{array}$ & $\begin{array}{l}18.3 \\
23.7\end{array}$ & $\begin{array}{l}17.4-19.4 \\
21.6-28.8\end{array}$ & $\begin{array}{l}9.0 \\
9.2\end{array}$ & $\begin{array}{l}8.5-9.5 \\
9.0-10.2\end{array}$ & $\begin{array}{l}20 \\
22-23\end{array}$ & $\begin{array}{l}\mathbf{3 7 . 0} \\
\mathbf{3 7 . 0}\end{array}$ & Ether & 1.15 & 0.96 \\
\hline J. D. & $\begin{array}{l}\mathbf{C} \\
\mathbf{A}\end{array}$ & $\begin{array}{l}23.9 \\
29.4\end{array}$ & $\begin{array}{l}16.9-27.7 \\
19.7-34.4\end{array}$ & & & $\begin{array}{l}11-12 \\
10-11\end{array}$ & $\begin{array}{l}36.5 \\
36.5\end{array}$ & Penth & - & - \\
\hline S. W.2 & $\begin{array}{l}\text { C } \\
\text { A }\end{array}$ & $\begin{array}{l}19.2 \\
40.8\end{array}$ & $\begin{array}{l}16.5-21.7 \\
22.8-59.4\end{array}$ & & & $\begin{array}{l}13-14 \\
13-15\end{array}$ & $\begin{array}{l}36.6 \\
36.5\end{array}$ & Penth & 0.67 & \\
\hline
\end{tabular}

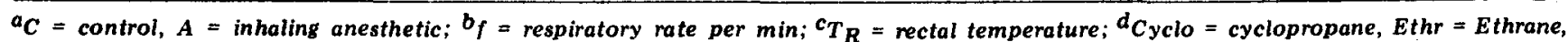
Penth $=$ Penthrane; $e_{I}=$ inspired, $E_{T}=$ end-tidal concentration (percent) .

concentration was within $0.1 \%$ to $0.2 \%$ of the inspired concentration. This condition was reached in 35 to $45 \mathrm{~min}$. No attempt was made to achieve equilibrium with ether or Ethrane. They were administered for $1 \frac{1}{2}$ to $2 \mathrm{~h}$, and inspired concentrations were adjusted to produce stable end-tidal concentrations. At this stage, we obtained a second set of data. Finally, the $S$ breathed room air for at least $30 \mathrm{~min}$ before we took our third and last set of observations. He then was removed to the hospital recovery room, where he was kept under observation until ready for discharge.

$S s$ in the first three studies produced intervals of 20,40 , and $60 \mathrm{sec}$, each four times per condition in a random order. Results showed the same effect for all three intervals. In order to minimize inhalation of anesthetics, we had the Ss in the next four studies produce only the 20-sec interval, four times per test. This interval yielded adequate samples of EEG for determining alpha frequency. Analysis of the data suggested that anesthetics change only the slope of the plot of produced time against objective time. To test this suggestion carefully, $S s$ in the final three studies produced intervals of $3,6,10,20,40$, and $60 \mathrm{sec}$, four times each in a random order under each experimental condition.

\section{RESULTS}

Table 1 shows results from each study for control (C) and anesthetic (A) conditions. Due to individual differences in reaction to anesthetics, recovery data did not return consistently to control levels. We expected the recovery data to be variable, and we will not show these results.

Medians and ranges of productions for the 20-sec interval appear in Table 1 . In each study, the $\mathrm{S}$ increased the interval produced during inhalation of anesthetic over that produced in control conditions. Eight of the 10 studies gave nonoverlapping ranges for productions during the two conditions. A one-tailed sign test showed that production of $20 \mathrm{sec}$ increased significantly $(p \leqslant .01)$ during anesthetic conditions. In marked contrast, alpha frequency, respiratory rate, and body temperature did not change consistently across Ss between conditions. Alpha frequency was measured at the beginning, the middle, and the end of each production; the median of these three determinations was taken. We thus obtained an alpha frequency for each of the four productions under a given condition. Table 1 shows the medians and ranges for these determinations. The table also shows the range of respiratory rates observed over each set of productions. Rectal temperature stayed constant within each set of productions, so that the table gives only single values for this index. Ss exposed to Penthrane did not show sufficient alpha activity for reliable frequency measurements. The high potency and high blood/gas solubility of this drug prevented measurement of end-tidal concentrations. Ss breathed this drug for at least $2 \mathrm{~h}$ before time productions were obtained.

If the alpha rhythm drives the internal clock, alpha frequency should decrease as time productions increase. Table 1 shows that alpha frequency increased in only four of the eight studies in which we could measure it. Respiratory rate similarly showed inconsistent changes across Ss. Rectal temperature tended to remain constant. Thus, inhalation of low concentrations of anesthetics can break the correlation between time judgments and body temperature. Heart rate (not shown in Table 1) remained constant in five studies, fell slightly in two, and dropped markedly in three. In summary, none of the physiological indices which we determined kept steady pace with alterations in time production.

If anesthetics alter time production by slowing an internal clock, we should expect them to increase the slope but not the intercept of a plot showing produced time, $t_{p}$, against objective time, $t_{o}$. We made such plots for the six sessions where Ss produced three or seven different objective intervals. The data from control conditions for a given session fell on one straight line, while those from anesthetic conditions fell on another. The lines seemed to converge at a single vertical intercept just above the origin. Anesthetics, however, markedly increased the slope of the plot. Figure 1 shows a typical example. Table 2 presents the slopes and 
Produced Time as a Function of Objective Time: Slopes, Intercepts, Alpha Frequencies, and Ratios of Slopes

\begin{tabular}{|c|c|c|c|c|c|c|c|c|c|}
\hline \multirow[b]{2}{*}{$\mathbf{S}$} & \multicolumn{2}{|c|}{$\begin{array}{c}\text { Slope } \\
\left(\Delta t_{p} / \Delta t_{o}\right)^{c}\end{array}$} & \multicolumn{2}{|c|}{ Intercept } & \multicolumn{2}{|c|}{$\begin{array}{l}\text { Median Alpha } \\
\text { Frequency }\end{array}$} & \multirow{2}{*}{$\frac{\text { Slope }}{\text { Obt. }}$} & \multirow{2}{*}{$\frac{\text { Ratio }^{\mathrm{a}}}{\text { Pred. }}$} & \multirow[b]{2}{*}{ Drug $^{b}$} \\
\hline & $\mathrm{C}$ & $\mathbf{A}$ & $\mathbf{C}$ & $\mathbf{A}$ & c & $\mathbf{A}$ & & & \\
\hline B. c. $d$ & 0.9 & 1.1 & 0.6 & 0.6 & 9.5 & 9.5 & 1.2 & 1.0 & Cyclo \\
\hline J. C. $2^{\mathrm{d}}$ & 1.0 & 1.2 & 0.1 & 0.1 & 9.0 & 9.2 & 1.2 & 0.98 & Ether \\
\hline J. D. & 1.0 & 1.2 & 0.4 & 0.4 & - & - & 1.2 & - & Penth \\
\hline S. W. $1^{\mathrm{e}}$ & 0.22 & 0.39 & 1.0 & 1.0 & 9.5 & 9.5 & 1.8 & 1.9 & Cyclo \\
\hline R. E. $e^{-}$ & 1.0 & 1.3 & 0.5 & 0.5 & 9.5 & 9.0 & 1.3 & 1.1 & Cyclo \\
\hline M. o.e & 0.51 & 0.84 & 1.8 & 1.7 & 10.5 & 9.2 & 1.6 & 1.1 & Cyclo \\
\hline
\end{tabular}

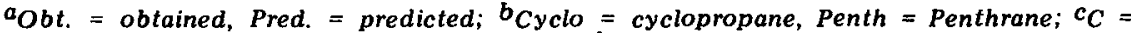
control, $A=$ during inhalation of anesthetic; dproduced $3,6,10,15,20,40$, and 60 sec; eproduced 20, 40, and $60 \mathrm{sec}$.

intercepts for each study during control and anesthetic conditions. The lines generating these parameters were fitted by eye. Notice the individual differences between Ss. M.O. and S.W.1 underestimated time in all circumstances, while R.E. and J.D. were quite accurate during control determinations. S.W.1 and S.W.2 in Table 1 are the same Ss studied on two occasions separated by a 2-month interval. This $\mathbf{S}$ was more accurate during his second study, probably because we informed him of his performance when he asked about it after the first study.

Reference to Table 1 shows that only R.E. and M.O. in Table 2 displayed decreased alpha frequency during inhalation of anesthetics. We made a further test to see whether diminished alpha frequencies could account for the performances of these two Ss in time production. The test supposes that the alpha rhythm drives the internal clock at frequency $f$. Then, for any produced time interval, $\Delta t_{p}$, as a response for a given objective interval, $\Delta t_{o}$,

$$
\mathbf{f} \cdot \Delta \mathbf{t}_{\mathbf{p}}=\mathbf{n}
$$

where $\mathbf{n}$ is the number of alpha cycles which the clock "counts" during the produced time interval. For control (C) and anesthetic (A) conditions,

$$
\mathbf{f}_{\mathrm{C}} \cdot \Delta \mathrm{t}_{\mathrm{pC}}=\mathbf{n}
$$

and

$$
\mathrm{f}_{\mathrm{A}} \cdot \Delta \mathrm{t}_{\mathrm{pA}}=\mathrm{n}
$$

In the last two equations, $f_{C}$ and $f_{A}$ are alpha frequencies during control and anesthetic conditions, respectively, and $\Delta t_{p C}$ and $\Delta t_{p A}$ are the corresponding produced time intervals. Dividing Eq. 2 by Eq. 3 and rearranging terms yields

$$
\Delta \mathrm{t}_{\mathrm{pA}} / \Delta \mathrm{t}_{\mathrm{pc}}=\mathrm{f}_{\mathrm{C}} / \mathrm{f}_{\mathrm{A}}
$$

It follows that

$$
\frac{\Delta t_{p A} / \Delta t_{o}}{\Delta t_{p C} / \Delta t_{o}}=\frac{f_{C}}{f_{A}}
$$

$\Delta \mathrm{t}_{\mathrm{pA}} / \Delta \mathrm{t}_{\mathrm{o}}$ and $\Delta \mathrm{t}_{\mathrm{p}} \mathrm{c} / \Delta \mathrm{t}_{\mathrm{o}}$ are, respectively, the slopes of the lines representing produced time as a function of objective time for anesthetic and control conditions, respectively. Table 2 includes the predicted and observed ratios of these slopes for Ss R.E. and M.O. The obtained ratios are much larger than the predicted ones. These results also argue against the alpha rhythm as the pendulum of the internal clock. Finally, for completeness, Table 2 also of slopes for the three Ss whose alpha frequencies did not drop during inhalation of anesthetic.

\section{DISCUSSION}

All Ss produced longer time intervals while breathing anesthetics. This confirms similar observations with nitrous oxide which Frankenhaeuser (1959) and Robson et al (1960) made. All anesthetics studied thus far at low concentrations influence the sense of time in the same way. Furthermore, our data indicate that these drugs increase the slope of the function which shows produced time against objective time. The anesthetics do not alter the linearity and do not obviously increase the intercept of this linear function. These observations incidentally confirm the finding of Frankenhaeuser (1958) and Carlson and Feinberg (1968) of a linear relationship between produced and objective time.

Our results thus suggest that anesthetics decelerate an internal clock if one exists. They also contradict the thesis (Holubar, 1969) that the alpha rhythm is the pendulum for the clock. Consistent changes in time productions during inhalation of anesthetics were not matched by consistent changes in alpha frequency. One possible escape from this situation is to argue that our results obtained during drug conditions reflect lapses of attention to the displays predicted and obtained ratios

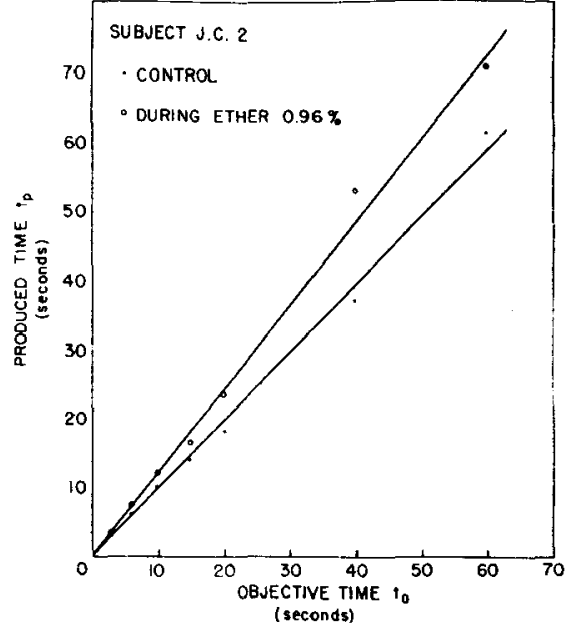

Fig. 1. Produced time against objective time before and during inhalation of ether (S J.C.2).

internal clock. This argument would predict inconsistent relationships between time productions and alpha frequency. It also would predict greatly increased variability of time production during inhalation of anesthetics. Although some studies yielded increased variability during administration of drugs, others (R.E., R.H., and S.W.1) clearly did not. Thus, changes in time production without corresponding shifts in alpha frequency did occur in some cases where inatlention seems not to have occurred.

Finally, our data indicate that changes in heart rate, respiratory rate, or body temperature cannot account for the increased time productions in response to anesthetics. None of these physiological variables changed consistently during drug conditions. Indeed, the anesthetics seemed to decouple time judgment from body temperature.

\section{REFERENCES}

ANLIKER, J Variations in alpha voltage of the electroencephalogram and time perception. Science, 1963, 140, 1307.

CARLSON, V. R., \& FEINBERG, I. Individual variations in time judgment and the concept of an internal clock. Journal of Experimental Psychology. 1968, 77, 631-640.

CLARK D. L. BUTLER, R. A. \& ROSNER, B. S. Dissociation of sensation and evoked responses by a general anesthetic in man. Journal of Comparative \& Physiological Psychology, $1969,68,315-319$

FRANCOIS, $M$. Contribution à l'étude de sens du temps. La température interne comme facteur de variation de l'appréciation subjective des durées. L'Année Psychologie, 1927, 28, 186-204. FRANKENHAEUSER, M. Estimation of time. Stockholm: Almquist \& Wiksell, 1959.

HAWKES, G. R.. JOY, R. J. T., \& EVANS, W. $O$. Autonomic effects on estimates of time: Evidence for a physiological correlate of temporal experience. Journal of Psychology, 1962,53,183-191. 
HILL, D. W. The application of gas chromatography to anesthetic research. In R. P. W. Scott (Ed.), Gas chromatography. London: Butterworth, 1960.

HOAGLAND, H. The physiological control of judgements of duration: Evidence for a chemical clock. Journal of General Psychology, 1933, 9, 267-286.

HOAGLAND, H. Pacemakers of human brain waves in normals and in general paretics. American Journal of Physiology, $1936,116,604-615$.

HOLUBAR, J. The sense of time: Electrophysiological study of its mechanisms in man. Cambridge: M.I.T. Press, 1969.

KLEBER, R. J., \& LHAMON, W. T. Hyperthermia, hyperthyroidism and time judgement. Journal of Comparative \& Physiological Psychology, 1963, 56, 362-365.
PFAFF, D. Effects of temperature and time of day on time judgements. Journal of Experimental Psychology, 1968, 76. 419-42.

ROBSON, J G., BURNS, B., \& WEET, P. J. L. The effect of inhaling dilute nitrous oxide upon recent memory and time estimation. Canadian Anaesthetists Society Journal, 1960, 7, 399-410.

(Accepted for publication February 15, 1971.) 